\title{
Emulsion Eye Drops Dosage Form
}

National Cancer Institute

\section{Source}

National Cancer Institute. Emulsion Eye Drops Dosage Form. NCI Thesaurus. Code C149498.

Liquid sterile single-dose or multidose preparation consisting of an emulsion intended for ocular use. Multidose preparations are presented in containers that allow successive drops to be administered. 